\title{
Dual-Energy Computed Tomography in Diffuse Liver Diseases
}

\author{
Uday Kumar Marri ${ }^{1}$ Kumble Seetharama Madhusudhan ${ }^{1}$
}

${ }^{1}$ Department of Radiodiagnosis and Interventional Radiology, All India Institute of Medical Sciences, New Delhi, India

J Gastrointestinal Abdominal Radiol ISGAR 2022;5:94-106.
Address for correspondence Kumble Seetharama Madhusudhan, MD, FRCR, Department of Radiodiagnosis and Interventional Radiology, All India Institute of Medical Sciences, New Delhi 110029, India (e-mail: drmadhuks@gmail.com).

\begin{abstract}
Keywords

- dual-energy computed tomography

- diffuse liver disease

- chronic liver disease

- hepatic steatosis

- liver iron

- liver fibrosis

Dual-energy computed tomography (DECT) is an advancement in the field of $\mathrm{CT}$, where images are acquired at two energies. Materials are identified and quantified based on their attenuation pattern at two different energy beams using various material decomposition algorithms. With its ability to identify and quantify materials such as fat, calcium, iron, and iodine, DECT adds great value to conventional CT and has innumerable applications in body imaging. Continuous technological advances in CT scanner hardware, material decomposition algorithms, and image reconstruction software have led to considerable growth of these applications. Among all organs, the liver is the most widely investigated by DECT, and DECT has shown promising results in most liver applications. In this article, we aim to provide an overview of the role of DECT in the assessment of diffuse liver diseases, mainly the deposition of fat, fibrosis, and iron and review the most relevant literature.
\end{abstract}

\section{Introduction}

Dual-energy computed tomography (DECT) is a significant advancement in the field of computed tomography (CT), where images are acquired at two different energies (kilovolts) and "material decomposition" algorithms are used to differentiate and quantify various materials with different effective atomic numbers such as water, fat, iron, and iodine in a given pixel. The concept of dual-energy acquisition and its potential benefits were first described in 1973 by Hounsfield in his original article on CT systems. ${ }^{1}$ However, a lot of technical difficulties had to be overcome before his vision was realized when the first clinical DECT scanner was introduced in 2006. ${ }^{2}$ Since then, all major CT manufacturers have introduced DECT scanners with different machine designs and image processing softwares.

published online February 8, 2022
DOI https://doi.org/ $10.1055 / \mathrm{s}-0042-1742432$. ISSN 2581-9933.
Diffuse liver disease, particularly cirrhosis, is a growing public health problem worldwide and is associated with significant morbidity and mortality. ${ }^{3}$ Liver biopsy is currently the gold standard for diagnosis (presence of inflammation, fibrosis, fat, iron) and staging of chronic liver parenchymal diseases. ${ }^{4}$ However, it is invasive, associated with hemorrhagic complications, and subject to sampling errors and inter-observer variations. ${ }^{5,6} \mathrm{~A}$ repeat biopsy to monitor the course of the disease and assess response to treatment is unjustified and has low acceptance among patients. Hence, there is a need for a reliable, reproducible, and non-invasive alternative. Magnetic resonance imaging (MRI) with its versatile techniques and sequences is increasingly becoming a well-established and accurate imaging tool for the purpose of assessing fat, fibrosis, and iron deposition. ${ }^{7-9}$ However, MRI is expensive, takes a long time to scan compared to CT or
(C) 2022. Indian Society of Gastrointestinal and Abdominal Radiology. All rights reserved.

This is an open access article published by Thieme under the terms of the Creative Commons Attribution-NonDerivative-NonCommercial-License, permitting copying and reproduction so long as the original work is given appropriate credit. Contents may not be used for commercial purposes, or adapted, remixed, transformed or built upon. (https://creativecommons.org/ licenses/by-nc-nd/4.0/)

Thieme Medical and Scientific Publishers Pvt. Ltd., A-12, 2nd Floor, Sector 2, Noida-201301 UP, India 


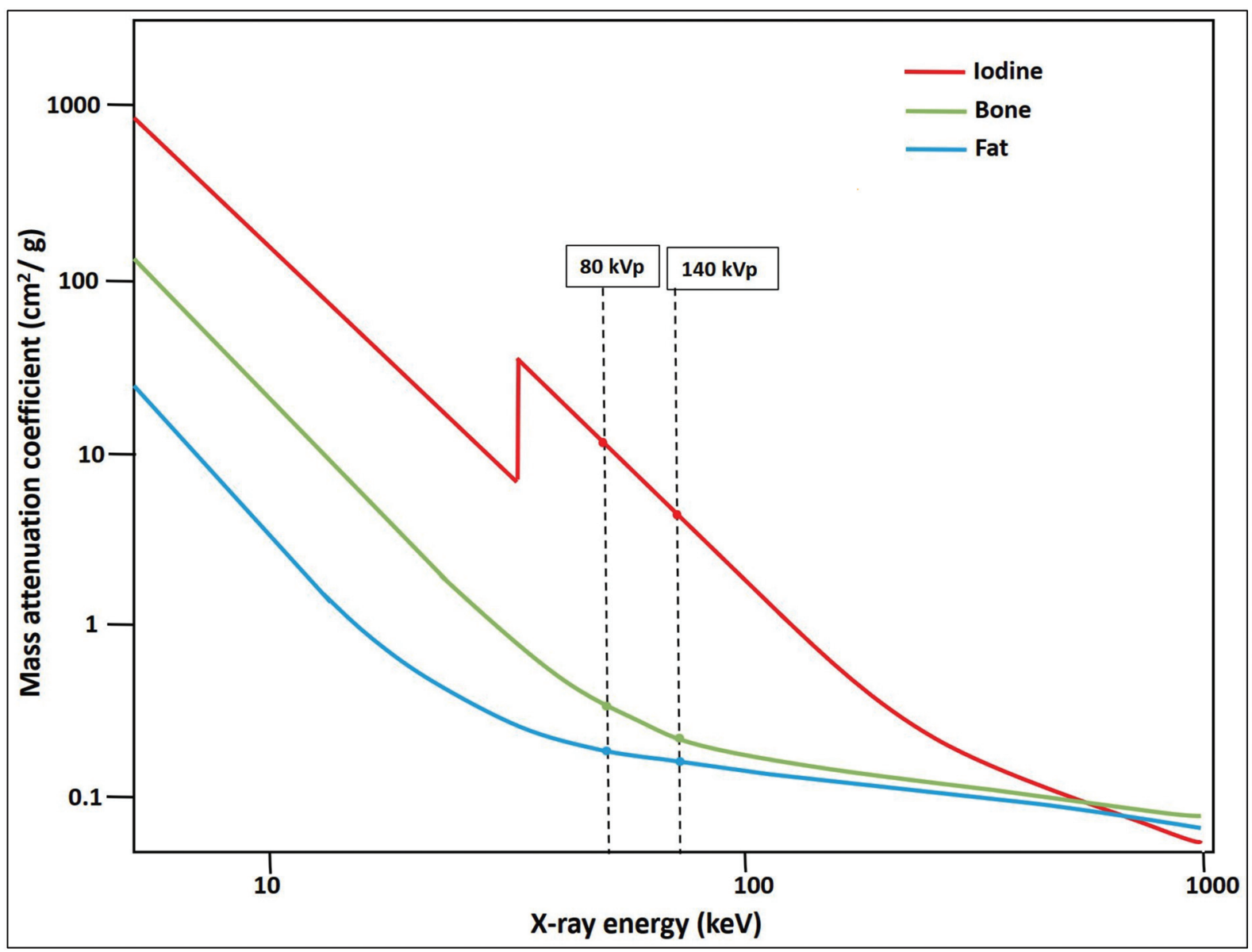

Fig. 1 Principle of dual-energy CT material decomposition algorithm to identify and quantify different materials. The graph shows a change in mass attenuation coefficients of iodine, bone (calcium), and fat at a wide range of X-ray energies. At specific X-ray energy, mass attenuation coefficient (linear attenuation coefficient/density) is only dependent on the effective atomic number of the medium. A difference in this coefficient at two different energy X-rays (for example $80 \mathrm{kVp}$ and $140 \mathrm{kVp}$ as shown in the graph) depends on the effective atomic number of the medium and not the medium density.

ultrasonography, and requires special sequences and hardware. Although the role of DECT in diffuse liver diseases is evolving, this article aims to review the most relevant literature on the use of DECT in the assessment of diffuse liver diseases, mainly the deposition of fat, fibrosis, and iron. We would also briefly discuss the basic principles of DECT image acquisition and image reconstruction with a focus on the areas that are relevant in the assessment of diffuse liver diseases.

\section{Basic Principles of DECT}

In CT, the photoelectric effect and Compton scattering are the dominant X-ray interactions influencing image formation. ${ }^{10}$ The attenuation of X-rays in each voxel is a function of the linear attenuation coefficient of the medium and energy of incident X-rays. The linear attenuation coefficient in turn depends on the effective atomic number of the medium and its material density. ${ }^{11,12}$ On a single-energy CT (SECT), materials with different atomic numbers may have the same CT attenuation value (Hounsfield unit [HU]) if the material densities are different. Hence, SECT cannot differentiate them. In DECT, using a second X-ray spectrum, two image datasets are produced, one from low energy and the other from high energy. The degree of attenuation change (attenuation coefficient) with a change in X-ray energy is independent of material density and is material specific. Materials such as fat, iodine, and bone have different degrees of attenuation change and can be identified based on this difference (-Fig. 1). With an appropriate software algorithm, these material-specific energy-dependent attenuation coefficients can also be used to quantify the mass density of two or three materials in a mixture of known material composition. ${ }^{13,14}$ Typically, the low-energy beam is 80 to $100 \mathrm{kVp}$ (kilovoltage peak) and the high energy beam is 120 to 150 $\mathrm{kVp}$. To generate the DECT image data, different approaches are followed, with modifications done either at the X-ray tube level or the detector level. These vendor-specific techniques of DECT scanners are described elsewhere in this issue.

Although the post-processing software of DECT is vendorspecific, in general, the workflows are not very different from each other. After the acquisition, the DECT images (either non-contrast or contrast-enhanced depending on the indication for which DECT is being performed) are transferred to the DECT workstation and loaded onto the dual-energy 


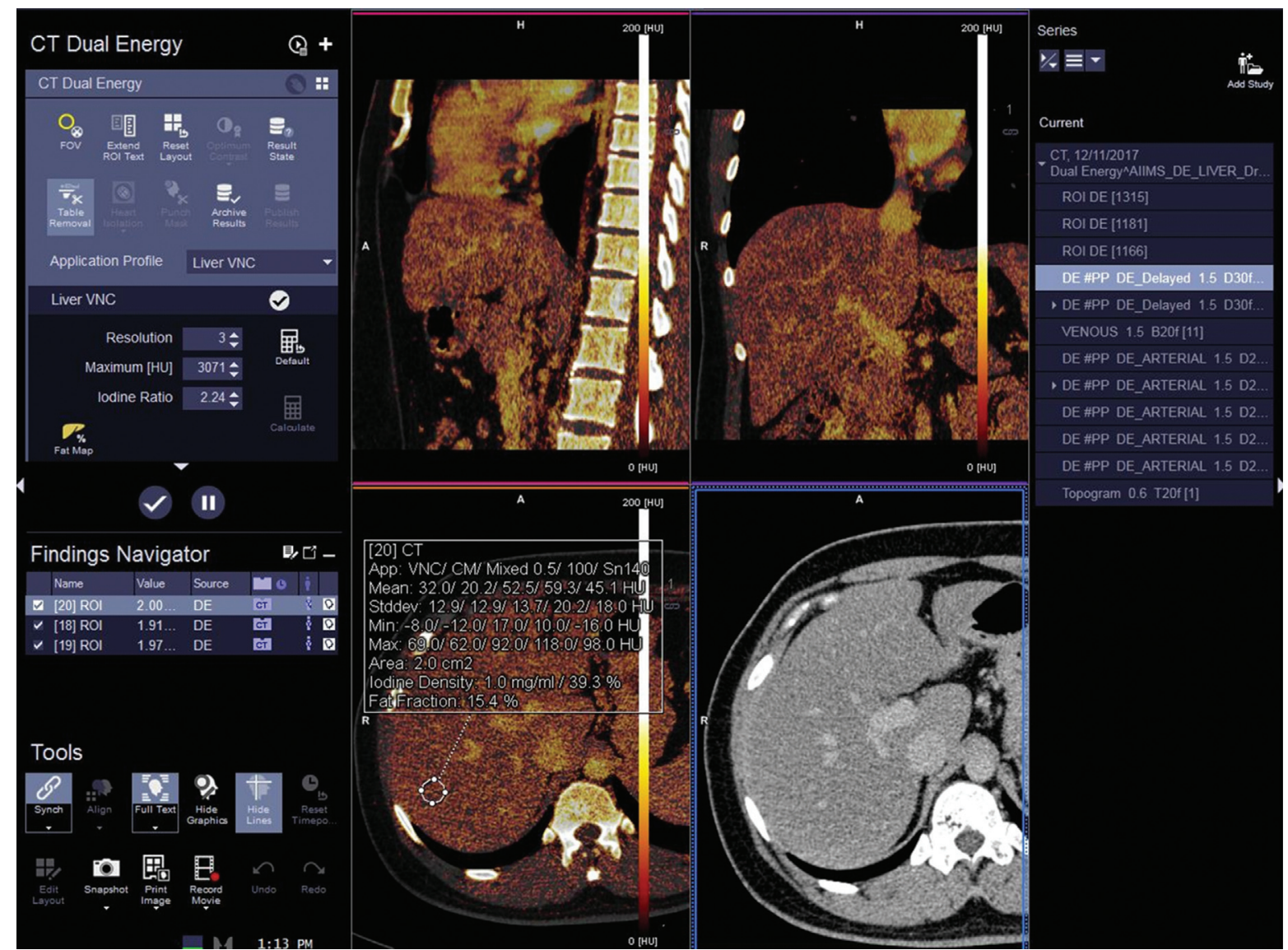

Fig. 2 Overview of dual-source dual-energy computed tomography (DECT) post-processing software (Syngo.via, version VB10B, 2016; Siemens Healthineers). Based on the material being evaluated, an appropriate application profile (in the left upper corner box) is chosen. Liver virtual non-contrast (VNC) is selected in this image to measure liver iodine concentration on the delayed phase DECT, for fibrosis quantification. The region of interest placed on the axial image shows various parameters including lodine density and fat fraction in that region. The same application can be used for liver fat quantification. Color-coded iodine maps are seen in three different planes.

software provided by the vendors. Various material-specific algorithms are inbuilt in the DECT software. The technique of quantification of a material is usually simple (-Fig. 2). The images are opened in the material-specific application and a region of interest (ROI) is drawn over the liver parenchyma avoiding major vessels. The ROI displays the concentration of the material, e.g., iodine or fat, being evaluated. Multiple ROIs may be drawn in different lobes and segments (at least three ROIs in each lobe) of the liver to get a mean of the values for reliable and reproducible results. Color-coded maps can also be generated for providing an overview of the distribution of the material in the liver parenchyma.

\section{Hepatic Steatosis}

Hepatic steatosis (HS) or fatty liver, currently is most commonly associated with non-alcoholic fatty liver disease (NAFLD). ${ }^{15}$ The other common causes of HS are alcohol consumption, ${ }^{16}$ hepatitis $C,{ }^{17,18}$ and use of certain medications including many chemotherapeutic agents ${ }^{19-21}$ and corticosteroids. $^{22}$ The estimated prevalence of HS is $~ 25 \%$ worldwide. ${ }^{23}$ NAFLD is frequently associated with metabolic syndrome, which comprises a set of risk factors for cardio- vascular disease and type II diabetes that include obesity, hypertension, elevated triglycerides, and insulin resistance. 24,25

Quantification of hepatic fat is important in patients with HS, as increasing steatosis leads to the development of steatohepatitis and then to cirrhosis with increased risk for the occurrence of hepato-cellular carcinoma and associated with poor liver surgical outcomes. ${ }^{26-28}$ However, with appropriate therapeutic strategies such as lifestyle modifications (dietary regulation and physical exercise) and drugs (pioglitazone and vitamin E), hepatic steatosis can be reversed along with the incidence of its metabolic complications. ${ }^{29}$ Hence, we need a reliable non-invasive modality for diagnosis, prognostication, and treatment monitoring in patients with HS. Chemical shift relaxometry and spectroscopy on MRI and backscatter coefficients or controlled attenuation parameters on ultrasonography (USG) are various imaging methods that can be used for liver fat quantification. ${ }^{30}$ MR spectroscopy (MRS) has proven to be the most accurate imaging tool and has the potential to replace biopsies. ${ }^{31}$ However, MRS can only quantify fat in a small area at a time and multiple measurements to cover the entire liver is a time-consuming process. Because of these reasons, 


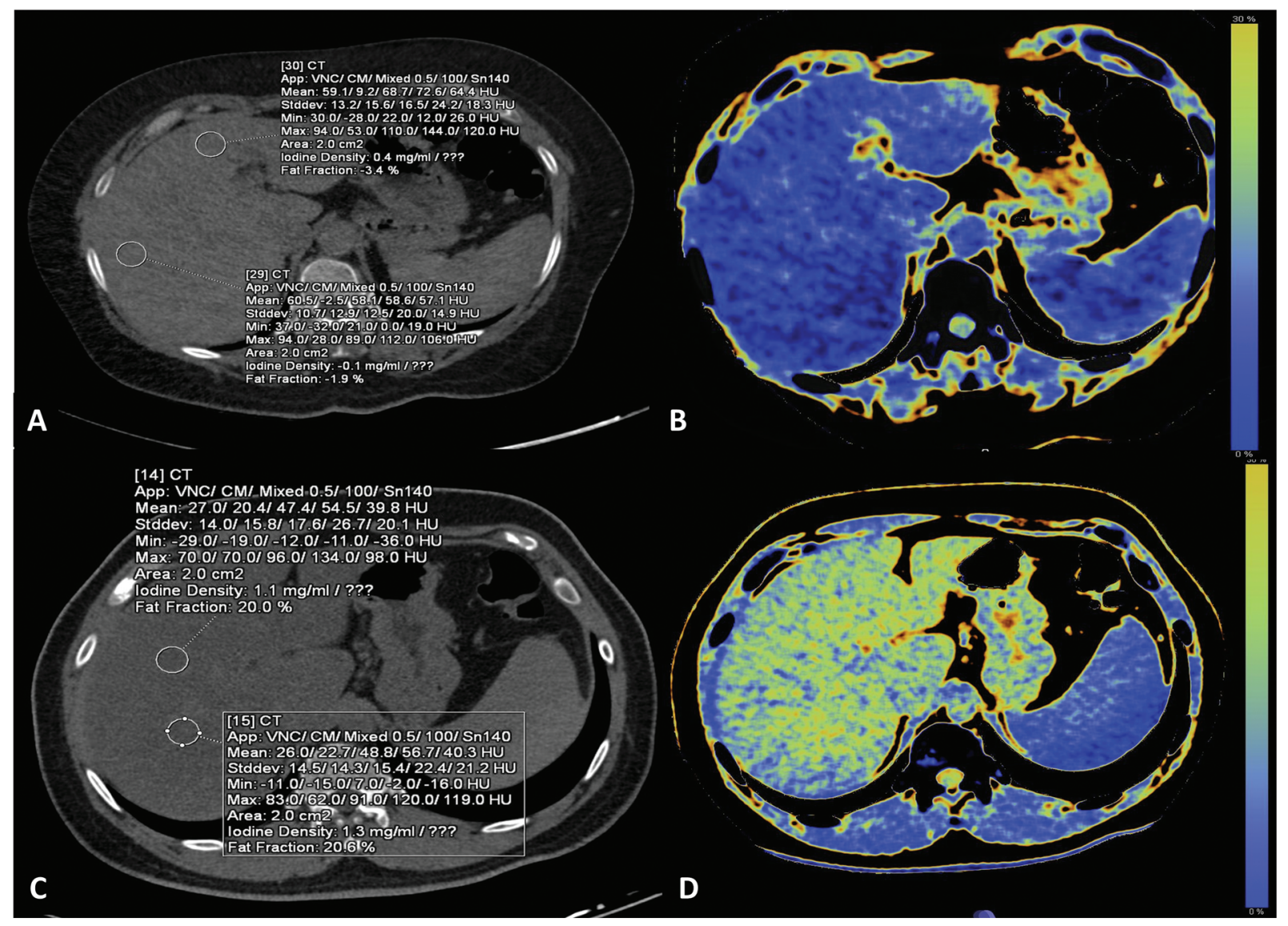

Fig. 3 Measurement of hepatic fat content on dual-source dual-energy computed tomography. (A, B) Axial virtual non-contrast (VNC) image of a patient (A) with normal liver parenchyma with two circular regions of interest (ROIs) drawn on the liver show close to zero fat fraction and corresponding color-coded fat map (B) shows almost no fat in the liver parenchyma. (C, D) Axial VNC image (C) of another patient with non-alcoholic fatty liver disease with two ROls show $20 \%$ of fat fraction and corresponding color-coded fat map (D) shows the distribution of fat in the liver parenchyma.

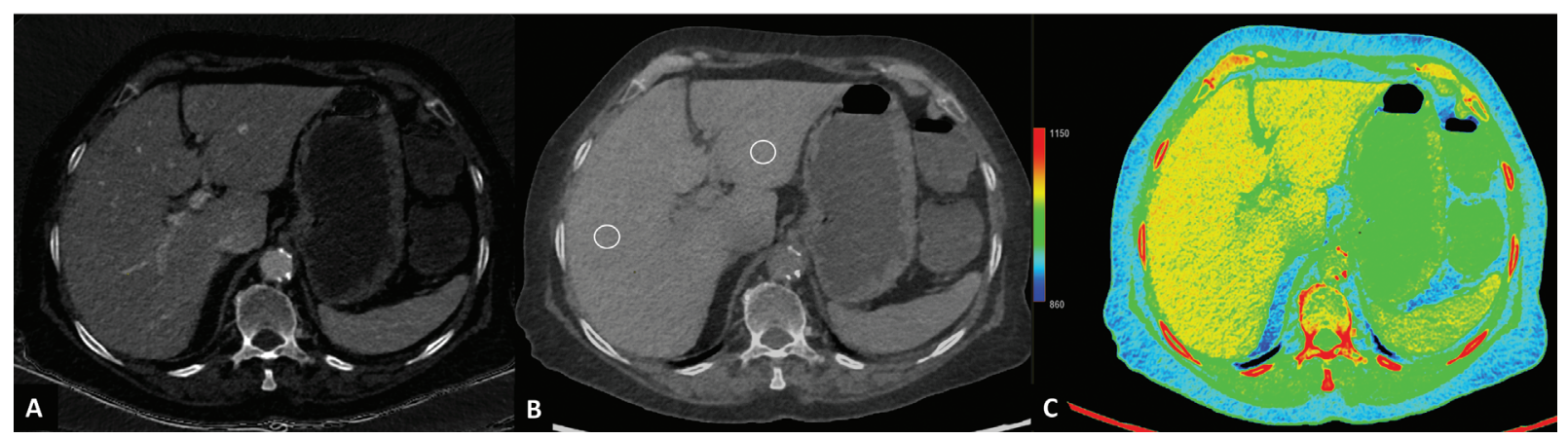

Fig. 4 Measurement of hepatic fat content on rapid switching dual-energy computed tomography. (A) Axial, contrast-enhanced image of the patient with fatty liver. (B) Virtual unenhanced image at the same level with two circular regions of interest. Mean attenuation was $32 \mathrm{HU}$ and fat fraction was $15.5 \%$. (C) The corresponding color-coded fat map shows the distribution of fat in the liver parenchyma.

MRS has been replaced by chemical shift imaging-derived proton density fat fraction (PDFF) as an imaging gold standard for liver fat quantification. ${ }^{9,32}$ However, the higher cost of MRI scan is the major limiting factor for its routine use. Ultrasound elastography is dependent on reference phantoms, prone to measurement errors especially in overweight female patients, and does not measure fat accurately as the values are influenced by co-existing fibrosis. ${ }^{33}$ However, the controlled attenuation parameter obtained on transient elastography (Fibroscan) has shown promising results in quantifying liver fat. ${ }^{34,35}$ In SECT, semiquantitative fat measurements can be performed using the attenuation value of the liver (HU), preferably on an unenhanced scan. ${ }^{36,37}$ However, absolute liver attenuation values can be affected by various factors such as CT acquisition parameters and the patient's cardiac and renal function. To overcome these, several authors have compared the attenuation of the liver to that of other abdominal organs and described various indices such as liver attenuation index (difference between liver and spleen attenuation) $)^{38-40}$ and $\mathrm{L} / \mathrm{S}$ ratio (ratio of liver 
Table 1 Brief details and summaries of results of studies evaluating dual-energy computed tomography in hepatic iron deposition

\begin{tabular}{|c|c|c|c|c|c|}
\hline Study (y) & $\begin{array}{l}\text { Sample } \\
\text { size } \\
\text { Cases/ } \\
\text { controls }\end{array}$ & $\begin{array}{l}\text { Modality of } \\
\text { comparison }\end{array}$ & $\begin{array}{l}\text { DECT } \\
\text { scanner type }\end{array}$ & $\begin{array}{l}\text { DECT } \\
\text { energies }\end{array}$ & Key results \\
\hline $\begin{array}{l}\text { Mendler et al } \\
\text { (1998) }\end{array}$ & $16 / 11$ & $\begin{array}{l}\text { DECT (non- } \\
\text { contrast) versus } \\
\text { USG and SECT }\end{array}$ & GE Pace-Plus & $80,140 \mathrm{kV}$ & $\begin{array}{l}\text { - Good correlation between liver - } \\
\text { spleen attenuation difference on } \\
\text { SECT and histology }(r=0.74) \\
\text { - No significant correlation between } \\
\triangle H U \text { on DECT and histology } \\
\text { - USG superior to SECT and DECT in } \\
\text { diagnosing fatty liver }\end{array}$ \\
\hline $\begin{array}{l}\text { Zheng et al. } \\
\text { (2013) }\end{array}$ & $32 / 20$ & $\begin{array}{l}\text { DECT versus USG } \\
\text { and SECT }\end{array}$ & $\begin{array}{l}\text { GE Discovery } \\
\text { CT } 750 \text { HD }\end{array}$ & $80,140 \mathrm{kV}$ & $\begin{array}{l}\text { - Good correlation between DECT } \\
\text { fat percentage and liver spleen } \\
\text { attenuation difference on SECT } \\
(r=0.98) \\
\text { - DECT superior to SECT, with its } \\
\text { distinct mono-energetic spectral } \\
\text { curves with different steatosis } \\
\text { grades and ability to delineate } \\
\text { areas of fat infiltration on } \\
\text { subtraction images }\end{array}$ \\
\hline $\begin{array}{l}\text { Patel et al } \\
\text { (2013) }\end{array}$ & $107 / 229$ & $\begin{array}{l}\text { DECT (late } \\
\text { arterial phase) } \\
\text { and SECT }\end{array}$ & $\begin{array}{l}\text { GE Discovery } \\
\text { CT } 750 \text { HD }\end{array}$ & $80,140 \mathrm{kV}$ & $\begin{array}{l}\text { - Good correlation between liver } \\
\text { spleen attenuation difference on } \\
\text { SECT and DECT fat fraction } \\
(r=0.74, p<0.001) \\
\text { - Fat quantification on contrast } \\
\text { enhanced DECT accurate } \\
\text { (AUROC }=0.85)\end{array}$ \\
\hline $\begin{array}{l}\text { Kramer et al } \\
(2017)\end{array}$ & $50 / 0$ & $\begin{array}{l}\text { DECT (non- } \\
\text { contrast), MR- } \\
\text { PDFF, USG and } \\
\text { elastography } \\
\text { versus MRS }\end{array}$ & $\begin{array}{l}\text { GE Discovery } \\
\text { CT } 750 \mathrm{HD}\end{array}$ & $80,140 \mathrm{kV}$ & $\begin{array}{l}\text { - Moderate correlation between } \\
\text { DECT fat fraction and MRS } \\
\left(r^{2}=0.42 \text { for anterior liver }\right. \\
\text { segments, } r^{2}=0.26 \text { for posterior } \\
\text { liver segments) } \\
\text { - Excellent correlation between } \\
\text { SECT attenuation and MR-PDFF } \\
\text { with MRS }\left(r^{2}=0.86 \text { and } 0.99,\right. \\
\text { respectively) } \\
\text { - Ultrasound elastography showed } \\
\text { poor correlation with MRS } \\
\left(r^{2}=0.004\right)\end{array}$ \\
\hline $\begin{array}{l}\text { Hyodo et al } \\
(2017)\end{array}$ & $29 / 4$ & $\begin{array}{l}\text { DECT (late } \\
\text { arterial, portal } \\
\text { venous, and } \\
\text { delayed phases) } \\
\text { versus histology } \\
\text { and MRS }\end{array}$ & $\begin{array}{l}\text { GE Discovery } \\
\text { CT } 750 \text { HD }\end{array}$ & $80,140 \mathrm{kV}$ & $\begin{array}{l}\text { - DECT (unenhanced and contrast- } \\
\text { enhanced) correlated well with } \\
\text { histology } \\
\text { - No significant difference in DECT } \\
\text { fat fraction of unenhanced, } \\
\text { arterial, portal venous, and } \\
\text { delayed phases (not more than } 2 \% \text { ) } \\
\text { - In differentiating steatosis grade } 0 \\
\text { from } 1-3, \text { AUROC for DECT and } \\
\text { MRS were } 0.88 \text { and } 0.89, \\
\text { respectively. }\end{array}$ \\
\hline $\begin{array}{l}\text { Corrias et al } \\
(2021)\end{array}$ & $39 / 0$ & $\begin{array}{l}\text { DECT (late } \\
\text { arterial phase) } \\
\text { versus MR-PDFF }\end{array}$ & $\begin{array}{l}\text { GE Discovery } \\
\text { CT } 750 \text { HD }\end{array}$ & $80,140 \mathrm{kV}$ & $\begin{array}{l}\text { - No significant difference in DECT } \\
\text { fat fraction and MRI-PDFF (two } \\
\text { readers with correlation } \\
\text { coefficients, } 0.84 \text { and } 0.85 \text {, } \\
p<0.05 \text { ) } \\
\text { - Good inter-reader agreement for } \\
\text { both techniques. (kappa } \\
\text { coefficient - } 0.88 \text { for MRI-PDFF, } \\
0.97 \text { for DECT-FF, } p<0.05 \text { ) }\end{array}$ \\
\hline
\end{tabular}

Abbreviations: $\triangle H U$, difference in attenuation between low- and high-energy images; AUROC, area under receiver operating characteristic; DECT, dual-energy computed tomography; MR-PDFF, magnetic resonance proton density fat fraction; MRS, magnetic resonance spectroscopy; $r$, correlation coefficient; $r^{2}$, correlation of determination; SECT, single energy CT; USG, ultrasonography. 
to spleen attenuation), ${ }^{39,41}$ which produced better results. However, attenuation values on SECT are still influenced by the presence of iodinated contrast material or liver iron. Further, SECT is less sensitive in the detection of early HS (sensitivity ranges from 52 to $62 \%$ in cases with 10 to $20 \%$ fat). ${ }^{42}$

In DECT, with the help of the "material decomposition" algorithm, it is possible to not only identify but also quantify the liver fat in a defined region (-Figs. 3 and 4 ). ${ }^{12} \mathrm{~A}$ few studies have evaluated the role of DECT in the detection and quantification of liver fat (-Table $\mathbf{1}$ ).

The oldest study was by Mendler et al that showed that DECT- $\Delta \mathrm{HU}(\Delta \mathrm{HU}$-difference in attenuation between lowenergy and high-energy images) generated using the sequential technique, is inferior to both SECT liver-spleen attenuation difference and ultrasound. ${ }^{43}$ Hyodo et al reported that the area under the receiver operating characteristic (ROC) curve of DECT was 0.88 (95\% confidence interval: $0.74-0.98)$ in the detection of fatty liver with more than $5 \%$ fat in needle biopsy tissue. ${ }^{44}$ This was comparable to MRS (area under the ROC curve $=0.89$ ). A study by Kramer et al showed that non-contrast DECT had a moderate correlation with MRS $\left(r^{2}=0.423\right)$, whereas SECT had an excellent correlation with MRS $\left(r^{2}=0.856\right)$ in the quantification of hepatic fat. ${ }^{31}$ The authors concluded that noncontrast DECT does not improve the accuracy of fat quantification over conventional SECT. The reason for this was that material decomposition is less accurate in the differentiation of fat and water on non-contrast DECT compared with iodine and water on contrast-enhanced DECT. Corrias et al compared DECT and PDFF on MRI in quantifying fat in patients with post-chemotherapy HS. ${ }^{45}$ They found no statistically significant difference between these two modalities in fat quantification and showed an excellent inter-reader agreement of DECT (kappa $=0.97, p<0.05$ ). Patel et al evaluated liver fat density on contrast-enhanced DECT using spleenliver attenuation difference $<1 \mathrm{HU}$ on non-contrast SECT as the reference standard for steatosis. The DECT fat measurement correlated well with the reference standard, with an $r$ value of $0.74(p<0.001)$ and area under receiver operator curve of $0.847 .{ }^{46}$ The role of DECT in fat quantification was also evaluated in several phantom studies and animal studies with mixed results. ${ }^{47-53}$

Recent studies have shown that, unlike SECT, material decomposition on DECT can accurately quantify liver fat even on contrast-enhanced images. ${ }^{44-46}$ This is also supported by other studies which have shown high fidelity of HU values measured on virtual non-contrast (VNC) images compared with unenhanced $\mathrm{CT}$ within the liver and other abdominal organs. ${ }^{54-57}$ This is invaluable because most fatty livers are incidental on post-contrast images and plain scans are not acquired routinely. Hyodo et al suggested that among contrast phases, an equilibrium phase is the best alternative to non-contrast CT in liver fat quantification on DECT. ${ }^{44}$

DECT is a valid technique in quantifying liver fat and can be used reliably in all suspected cases of hepatic steatosis. It can be seamlessly integrated into abdomen CT scan protocols for liver fat quantification. Although a non-contrast scan is preferred, with the use of the latest multi-material algorithms, fat can be reliably quantified even on contrastenhanced CT scans.

\section{Liver Fibrosis}

Liver fibrosis is the common underlying pathological process in chronic liver diseases, regardless of the cause. This results from the excessive accumulation of the extracellular matrix. ${ }^{58}$ Progression of liver fibrosis parallels with the increase in portal pressure, which worsens the prognosis due to the associated complications. ${ }^{58}$ Hence, assessment of the severity of liver fibrosis has direct implications on the treatment, follow-up planning, and risk stratification in patients with chronic liver disease. ${ }^{3,59}$ For instance, in chronic viral hepatitis, the presence of bridging fibrosis on histology is a strong factor for the recommendation of antiviral therapy, whereas the presence of cirrhosis calls for an endoscopy for esophageal varices and also screening for hepatocellular carcinoma. ${ }^{4}$ This clinical significance of detection and grading of liver fibrosis has led to an active search for a non-invasive modality to quantify fibrosis in these patients.

Ultrasound elastography (transient and shear-wave elastography) techniques are simple, inexpensive, and accurate. However, their measurements are affected by the presence of ascites, obesity, biliary obstruction, acute inflammation, fatty liver, and narrow intercostal spaces. ${ }^{60-62}$ MR elastography is the most accurate non-invasive modality in quantifying liver fibrosis and correlates closest to the histological staging. ${ }^{60,63}$ Nonetheless, in spite of these advantages, the high cost, lack of accessibility, the requirement of dedicated hardware, and confounding effects by coexisting iron accumulation preclude its routine use.

DECT cannot directly detect or quantify fibrosis in the liver on non-contrast $\mathrm{CT}$ as it shows a similar attenuation pattern as the rest of the parenchyma. Several studies have attempted to quantify fibrosis by measuring extracellular volume fraction using liver attenuation values on contrastenhanced delayed phase SECT with good correlation with histology. ${ }^{64-67}$ The timing of the delayed phase CT in these studies was heterogeneous, ranging from 3 to 30 minutes. This is based on the hypothesis that fibrotic areas in the liver retain more contrast material in the delayed phase due to the increased extracellular space due to matrix deposition and reduced perfusion. ${ }^{66,68}$ This contrast retention is reflected by the concentration of iodine in the liver that can be readily measured on DECT. Therefore, the concentration of the iodine in the liver on delayed phase DECT directly correlates to the concentration of fibrous tissue in the liver. $\mathrm{Lv}$ et $\mathrm{al}^{69}$ evaluated the role of portal venous phase (obtained $30 \mathrm{sec}$ onds after the arterial phase was acquired by bolus triggering) DECT in 38 patients with cirrhotic livers (Child-Pugh class $\mathrm{A} / \mathrm{B} / \mathrm{C}: n=10 / 14 / 14)$ and 43 patients with healthy livers. In differentiating healthy liver from a cirrhotic liver, a cut-off value of 0.52 of the normalized iodine concentration (normalized iodine concentration [NIC], which is the ratio of iodine concentration of liver to that of the aorta) in the portal venous phase showed high sensitivity (95\%), but relatively 


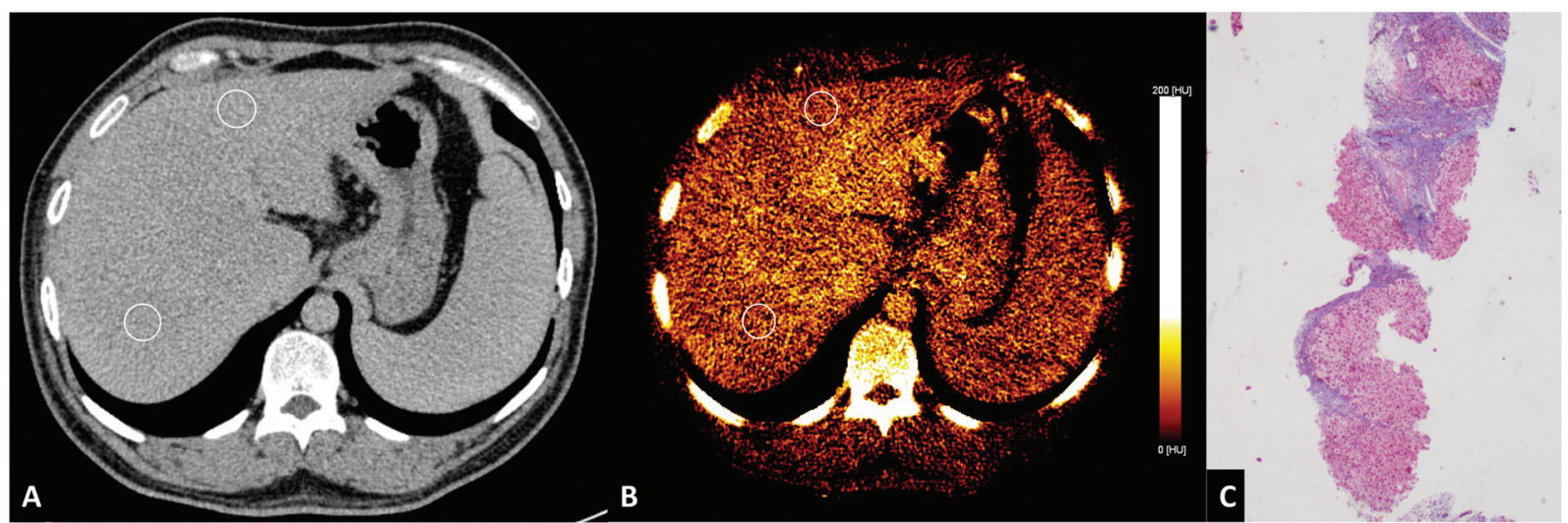

Fig. 5 Assessment of hepatic fibrosis on dual-source dual-energy computed tomography (DECT) in a 40-year-old man with chronic hepatitis B cirrhosis. (A) Axial 5-minute delayed phase DECT image with circular regions of interest (ROIs) in both lobes of the liver. Normalized iodine concentration (NIC) in the right and left lobes were 0.571 and 0.539 , respectively. (B) The iodine map of the delayed phase shows heterogeneous iodine uptake in the liver. (C) Histology of the biopsy sample showed a METAVIR stage of F4. The NIC values were consistent with cut-offs suggested by a recent study by Marri et al.

lower specificity (61\%). The iodine concentration (IC) ratio (iodine concentration of liver in the arterial phase to that in the portal vein phase) with a cut-off at 0.3 showed high sensitivity (79\%) but low specificity (49\%). However, a combination of these two parameters showed high sensitivity (77\%) and specificity (87\%).
Lamb et al ${ }^{12}$ found that NIC of liver on a 3-minute delayed phase DECT strongly correlated with Ishak fibrosis stage $(p<0.05)$. Fuentes et $\mathrm{al}^{70}$ in their retrospective study on 12 participants, showed a strong correlation between NIC in the delayed phase and Ishak fibrosis stage $(r=0.77, p<0.01)$. Sofue et $\mathrm{al}^{71}$ in a 47 -patient cohort showed that NIC had a

Table 2 Brief details and summaries of results of studies evaluating dual-energy CT in hepatic fibrosis

\begin{tabular}{|c|c|c|c|c|c|}
\hline $\begin{array}{l}\text { Study } \\
\text { (year) }\end{array}$ & $\begin{array}{l}\text { Sample } \\
\text { size } \\
\text { Cases/ } \\
\text { control }\end{array}$ & Modality of comparison & $\begin{array}{l}\text { DECT Scanner } \\
\text { type }\end{array}$ & $\begin{array}{l}\text { DECT } \\
\text { energies }\end{array}$ & Key results \\
\hline $\begin{array}{l}\text { Lv et al } \\
(2012)\end{array}$ & $38 / 43$ & $\begin{array}{l}\text { DECT - Portal venous } \\
\text { phase NIC and IC ratio } \\
\text { with Child-Pugh score }\end{array}$ & $\begin{array}{l}\text { GE Discovery } \\
\text { CT } 750 \text { HD }\end{array}$ & $80,140 \mathrm{kV}$ & $\begin{array}{l}\text { - NIC cut-off of } 0.52 \text { : high sensitivity ( } 95 \% \text { ) but } \\
\text { relatively low specificity ( } 61 \%) \text {. } \\
\text { - IC ratio with cut-off of } 0.3 \text { : high sensitivity (79\%) but } \\
\text { low specificity }(49 \%) \text {. } \\
\text { - High sensitivity ( } 77 \% \text { ) and specificity ( } 87 \%) \text { for } \\
\text { combination of NIC and IC ratio in differentiating } \\
\text { healthy liver from the cirrhotic liver. }\end{array}$ \\
\hline $\begin{array}{l}\text { Lamb et al } \\
\text { (2015) }\end{array}$ & $7 / 5$ & $\begin{array}{l}\text { DECT - 3-minute delayed } \\
\text { phase liver NIC with } \\
\text { histology }\end{array}$ & $\begin{array}{l}\text { GE Discovery } \\
\text { CT } 750 \text { HD }\end{array}$ & $80,140 \mathrm{kV}$ & $\begin{array}{l}\text { - NIC on DECT correlated with histology and allowed } \\
\text { statistically significant stratification of patients by } \\
\text { severity of fibrosis }(p<0.05 \text { for all stages) } \\
\text { - On two different time point scans, NIC showed a } \\
\text { high degree of repeatability }\left(r^{2}=0.93\right)\end{array}$ \\
\hline $\begin{array}{l}\text { Sofue et al } \\
\text { (2018) }\end{array}$ & $47 / 0$ & $\begin{array}{l}\text { DECT - 3-minute delayed } \\
\text { phase liver NIC with } \\
\text { histology }\end{array}$ & $\begin{array}{l}\text { GSI, GE } \\
\text { Discovery CT } \\
750 \text { HD }\end{array}$ & $80,140 \mathrm{kV}$ & $\begin{array}{l}\text { - NIC showed moderate correlation with METAVIR } \\
\text { stage }(r=0.63, p<0.001) \\
\text { In discriminating each fibrosis stage, AUROC for NIC } \\
\text { ranged from } 0.80 \text { to } 0.86\end{array}$ \\
\hline $\begin{array}{l}\text { Marri et al } \\
(2021)\end{array}$ & $107 / 50$ & $\begin{array}{l}\text { DECT - 5-minute delayed } \\
\text { phase liver NIC and } \\
\text { sonoelastography with } \\
\text { histology }\end{array}$ & $\begin{array}{l}\text { SOMATOM DF, } \\
\text { Siemens }\end{array}$ & $100,140 \mathrm{kV}$ & $\begin{array}{l}\text { - NIC showed strong correlation with METAVIR stage } \\
(r=0.81, p<0.001) \\
\text { - In discriminating each fibrosis stage, AUROC for NIC } \\
\text { ranged from } 0.86 \text { to } 0.96 \\
\text { - NIC showed good agreement with liver stiffness as } \\
\text { measured with transient elastography and shear } \\
\text { wave elastography ( } r=0.60 \text { and } 0.64 \text {, respectively, } \\
p<0.001) \\
\text { - 5-minute delayed phase showed better sensitivity } \\
\text { and specificity compared with 3-minute delay, which } \\
\text { was used in previous studies }\end{array}$ \\
\hline
\end{tabular}

Abbreviations: $\triangle \mathrm{HU}$, difference in attenuation between low- and high-energy images; AUROC, area under receiver operating characteristic; DECT, dual-energy CT; GSI, gemstone imaging; IC, iodine concentration; NIC, normalized iodine concentration; $r$, correlation coefficient; $r^{2}$, correlation of determination. 


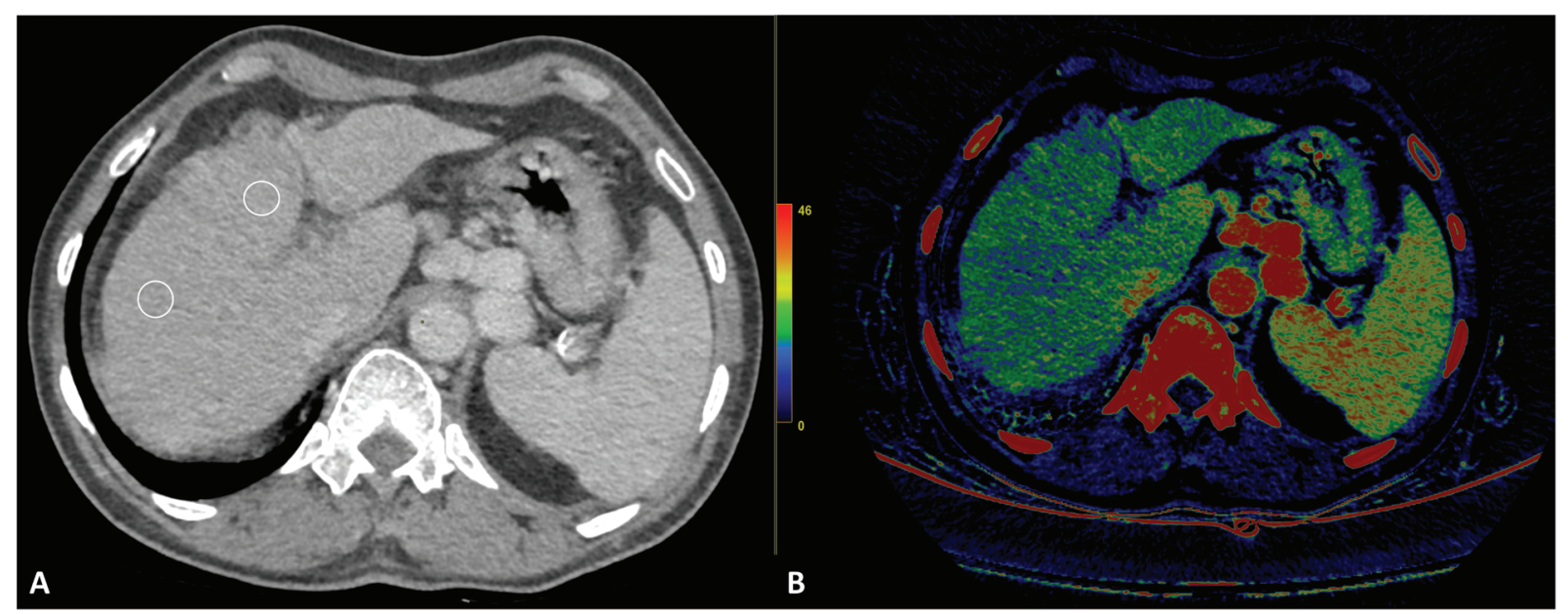

Fig. 6 Assessment of hepatic fibrosis on rapid switching dual-energy computed tomography (DECT) in a 46-year-old man with alcoholic cirrhosis. (A) Axial 5-minute delayed-phase DECT image with circular regions of interest (ROIs) in both lobes of the liver. Normalized iodine concentration in the right and left lobes were 0.490 and 0.513 , respectively, suggesting a stage of F4, according to Marri et al. (B) lodine map from the delayed phase shows heterogeneous iodine uptake in the liver.

good correlation with the METAVIR fibrosis stage $(r=0.65$, $p<0.001)$. The area under the receiver operating curve (AUROC) ranged from 0.79 to 0.86 in discriminating each liver fibrosis stage ( $\geq \mathrm{F} 1-\mathrm{F} 4)$. The NIC cut-off values for the diagnosis of METAVIR stages $\geq F 1, \geq F 2, \geq F 3$ and $=F 4$ were found to be $0.270,0.274,0.286$, and 0.299 with accuracies of $74.5 \%, 78.7 \%, 78.7 \%$, and $76.6 \%$, respectively. In a recent prospective study evaluating 107 patients of chronic liver disease by Marri et $\mathrm{al}^{68}$ in our institute, the NIC on the 5minute delayed phase DECT was compared with the METAVIR stage on histology (- Fig. 5). The NIC showed a high positive correlation with METAVIR fibrosis stage $(r=0.81$; $p<0.0001$ ). The AUROC for the NIC in the right lobe of the liver with respect to each METAVIR stage ranged from 0.86 to 0.96 . The cut-off values (with sensitivity and specificity) of NIC for different fibrosis stages were $\geq \mathrm{F} 1=0.243(85.1 \%$, $83.3 \%), \geq \mathrm{F} 2=0.289$ (83.7\%, 81.4\%), $\geq \mathrm{F} 3=0.343 \quad(86.9 \%$, $86.8 \%),=\mathrm{F} 4=0.401(93.3 \%, 84.7 \%)$, respectively. A 5-minute delayed DECT was used in this study in contrast to the previous studies, where a 3-minute delay was used. This longer delay had resulted in a better performance of DECT in fibrosis quantification and fewer overlapping NIC cut-offs for the METAVIR stages. DECT performance was also compared with elastography in this study. NIC showed good agreement with liver stiffness as measured with transient elastography and shear-wave elastography (Spearman $r=0.60$ and 0.64 , respectively; $p<0.001$ ). An overview of some of the studies is shown in - Table 2.

A significant number of patients with chronic liver disease routinely undergo multiphase CT scans of the abdomen as part of hepatocellular carcinoma surveillance. The possibility of grading the severity of fibrosis on the same scan would be invaluable. The addition of dual-energy acquisition in the contrast-enhanced delayed phase, preferably 5-minute, is suggested for this purpose (-Fig. $\mathbf{6}$ ). This could reduce the number of biopsies and related complications in these patients. Simultaneously, larger studies are needed to formulate a uniform CT acquisition protocol, delayed phase timing, and NIC cut-off values in each fibrosis stage in these patients.

\section{Hepatic Iron}

Liver iron deposition and chronic liver disease are interrelated. Deposition of iron in the liver parenchyma can be due to increased total body iron as seen in hereditary hemochromatosis or transfusion-related hemosiderosis. ${ }^{72}$ Conversely, liver diseases such as chronic viral hepatitis, alcoholic liver disease, and non-alcoholic steatohepatitis (NASH) also promote iron deposition in the liver. ${ }^{73,74}$ Increasing iron deposition in the hepatocytes causes liver damage by oxidative stress, eventually leading to cirrhosis and the possibility of the development of hepatocellular carcinoma (HCC). ${ }^{75} \mathrm{He}-$ patic iron deposition in chronic liver disease is also independently associated with increased mortality. ${ }^{76}$ Hence, liver iron detection and quantification are crucial for the management of these patients.

MRI is widely considered the primary modality for noninvasive liver iron quantification. Chemical shift imaging, the signal intensity of liver relative to spleen on fast-spin echo T2-weighted sequence, liver to muscle signal intensity ratio on multi-echo gradient recalled echo (GRE) sequence, and $\mathrm{R} 2$ and $\mathrm{R} 2 *$ relaxometry are the various MRI techniques used in accurate estimation of liver iron content. ${ }^{77,78}$ Among these, R2 relaxometry is the most validated and often considered as the gold standard. ${ }^{77}$ However, R2* relaxometry is more practical because the GRE sequence is faster, results are reliable, and simultaneous acquisition of fat and iron is possible in a single breath-hold. ${ }^{78}$ Apart from the high cost and inaccessibility to MRI machine and post-processing software, the variability of the results in the presence of high concentrations of liver iron is a limitation.

On DECT, unenhanced CT is preferred for iron quantification. Liver iron is quantified either by using the attenuation difference of the liver between the low- and high-energy CT 
Table 3 Brief details and summaries of results of studies evaluating dual-energy computed tomography in hepatic iron deposition

\begin{tabular}{|c|c|c|c|c|c|}
\hline Study (year) & $\begin{array}{l}\text { Sample } \\
\text { size } \\
\text { Cases/ } \\
\text { controls }\end{array}$ & $\begin{array}{l}\text { Modality of } \\
\text { comparison }\end{array}$ & $\begin{array}{l}\text { DECT } \\
\text { Scanner } \\
\text { type }\end{array}$ & DECT energies & Key results \\
\hline $\begin{array}{l}\text { Joe et al. } \\
(2011)\end{array}$ & $87 / 0$ & $\begin{array}{l}\text { DECT- } \triangle H U \text { and } \\
\text { MRI (T1 IP and OP, } \\
\text { and HASTE) with } \\
\text { histology }\end{array}$ & $\begin{array}{l}\text { SOMOTOM } \\
\text { D, Siemens }\end{array}$ & $80,140 \mathrm{kV}$ & $\begin{array}{l}\text { - Significant correlation of DECT- } \Delta H U \\
\text { with degree of liver iron } \\
\text { accumulation ( } r=0.43, p<0.01) \\
\text { - AUROC for clinically significant iron } \\
\text { accumulation with DECT and MRI } \\
\text { were } 0.88 \text { and } 0.89 \text {, respectively. }\end{array}$ \\
\hline $\begin{array}{l}\text { Luo et al. } \\
(2015)\end{array}$ & $56 / 0$ & $\begin{array}{l}\text { DECT- material } \\
\text { decomposition } \\
\text { (VIC) with } R 2 \text { and } \\
\text { R2* technique }\end{array}$ & $\begin{array}{l}\text { SOMATOM } \\
\text { DF, Siemens }\end{array}$ & $80,140 \mathrm{kV}$ & $\begin{array}{l}\text { - Significant correlation between iron } \\
\text { content on DECT and R2* \& R2 MRI } \\
(r=0.89 \text { and } 0.87 \text {, respectively; } \\
p<0.001) \\
\text { - At liver iron content }>3.2 \mathrm{mg} / \mathrm{g} \text { of } \\
\text { dry tissue, DECT and MRI R } 2^{*} \text { similar } \\
\text { (AUROC, } 0.96 \text { vs. } 0.99 \text {, respectively; } \\
p=0.30)\end{array}$ \\
\hline $\begin{array}{l}\text { Werner et al. } \\
(2019)\end{array}$ & $99 / 48$ & $\begin{array}{l}\text { DECT - VIC with } \\
\text { serum ferritin and } \\
\text { estimated } \\
\text { transfused iron }\end{array}$ & $\begin{array}{l}\text { SOMATOM } \\
\text { DF, Siemens }\end{array}$ & $100,140 \mathrm{kV}$ & $\begin{array}{l}\text { - Good correlation between DECT iron } \\
\text { content and serum ferritin }(r=0.62 \text {, } \\
p<0.001)\end{array}$ \\
\hline $\begin{array}{l}\text { Ma et al. } \\
(2020)\end{array}$ & $31 / 0$ & $\begin{array}{l}\mathrm{DECT}-\triangle \mathrm{HU} \\
\text { and } \mathrm{MRI} \\
\text { (R2* technique) }\end{array}$ & IQon, Philips & $\begin{array}{l}\text { Tube voltage } \\
120 \mathrm{kVp} \\
\text { with dual-layer } \\
\text { spectral detector }\end{array}$ & $\begin{array}{l}\text { - Good correlation of DECT- } \Delta \mathrm{HU} \text { with } \\
\text { MRI liver R2* }(r=-0.83, p<0.001)\end{array}$ \\
\hline
\end{tabular}

Abbreviations: $\triangle \mathrm{HU}$, difference in attenuation between low- and high-energy images; AUROC, area under receiver operating characteristic; DECT, dualenergy computed tomography; HASTE, half Fourier single-shot turbo spin echo; IP, in-phase; OP, opposed phase; $r=$ correlation coefficient; VIC, virtual iron content.

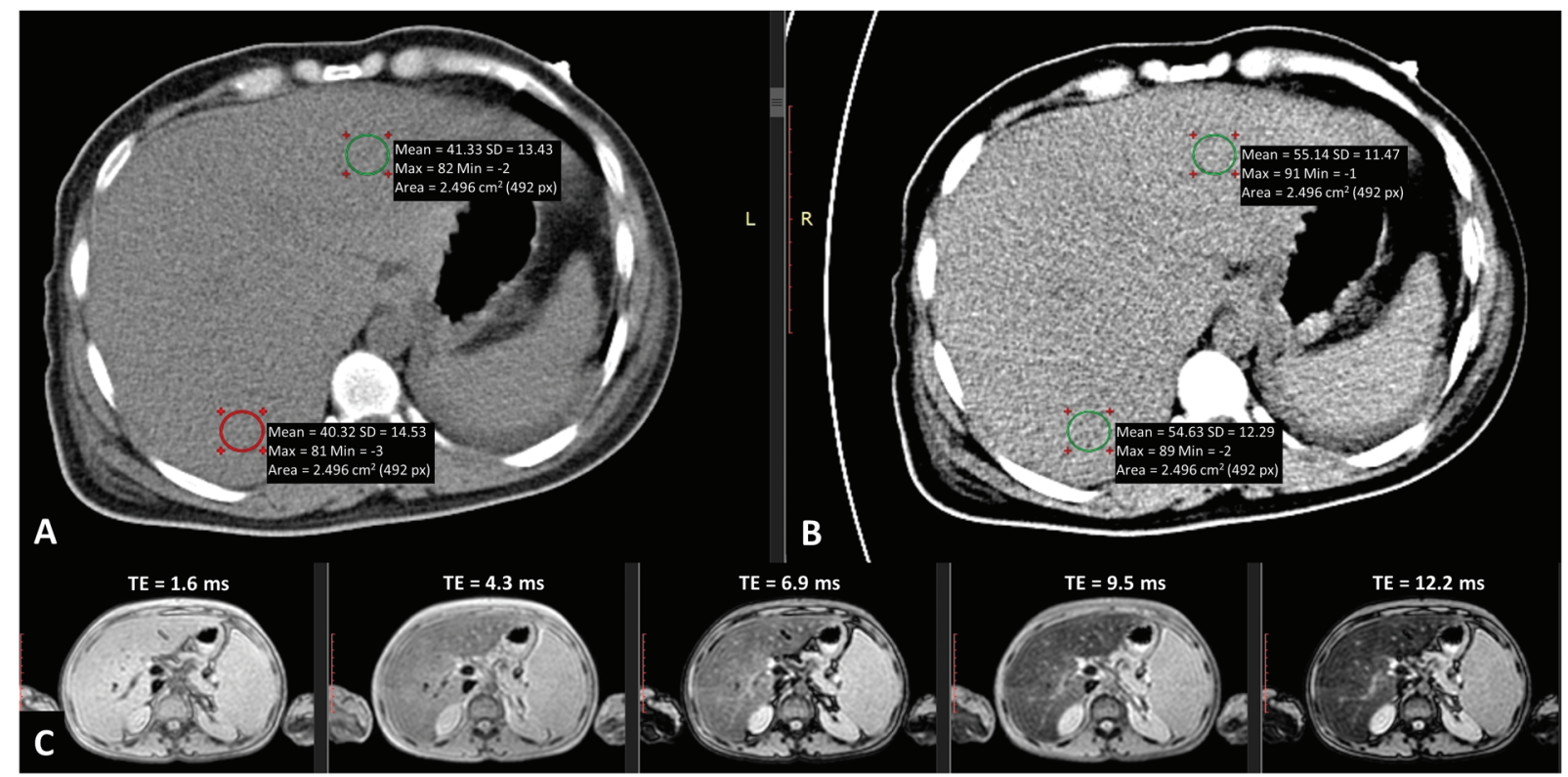

Fig. 7 Assessment of liver iron content on dual-source dual-energy computed tomography in a 19-year-old male patient with $\beta$ thalassemia. $(A, B)$ Axial high energy $(A, 140 \mathrm{kVp})$ and low energy $(B, 80 \mathrm{kVp})$ non-contrast images show a mean difference in attenuation of liver between the two energies $(\triangle \mathrm{HU})$ of $14.1 \mathrm{HU}$, suggesting iron deposition. (C) Axial multi-echo gradient MR images from a $3 \mathrm{~T}$ machine show a gradual decrease in liver signal with an increase in TE. The $T 2^{*}$ value was 10.3 milliseconds and $R 2^{*}$ was $163 / \mathrm{s}$ suggestive of moderate iron deposition.

images $(\Delta \mathrm{HU})$ or using an iron-specific material decomposition algorithm, which gives virtual iron content based on the attenuation difference ( $\mathbf{- T a b l e ~} \mathbf{3}$; - Fig. $\mathbf{7}$ ). Joe et al in their retrospective study showed that DECT- $\Delta \mathrm{HU}$ (difference of liver attenuation between 80 and $140 \mathrm{kVp}$ ) correlates well with the degree of iron accumulation $(r=0.43, p<0.001) .{ }^{79}$ The mean $\Delta \mathrm{H}$ was 13.53 in patients with clinically important ( $\geq 10 \%$ ) iron accumulation compared with 7.39 in normal 
Table 4 Summary of suggestions for practical application of DECT in diffuse liver diseases

\section{Dual-energy computed tomography: practical considerations}

- Most of the current published literature on the role of DECT in diffuse liver diseases has used a single-source DECT scanner with tube energies $80 \mathrm{kV}$ and $140 \mathrm{kV}$. There are not enough data comparing single-source DECT and dual-source DECT or different tube energies to prefer one over the other.

- When the iodinated contrast agent is used, the contrast volume, injection rate, and CT acquisition timings for DECT are the same as for conventional SECT. For liver fibrosis quantification, only a delayed phase CT (variably at 3 to 5 minutes) may be acquired in the dual-energy mode to avoid unnecessary data overload.

- For measuring any material density on DECT, we recommend drawing at least three circular regions of interest (ROIs) with a diameter measuring $2 \mathrm{~cm}$ in each liver lobe, avoiding major vessels or focal lesions, to account for the heterogeneous distribution and for reproducible results.

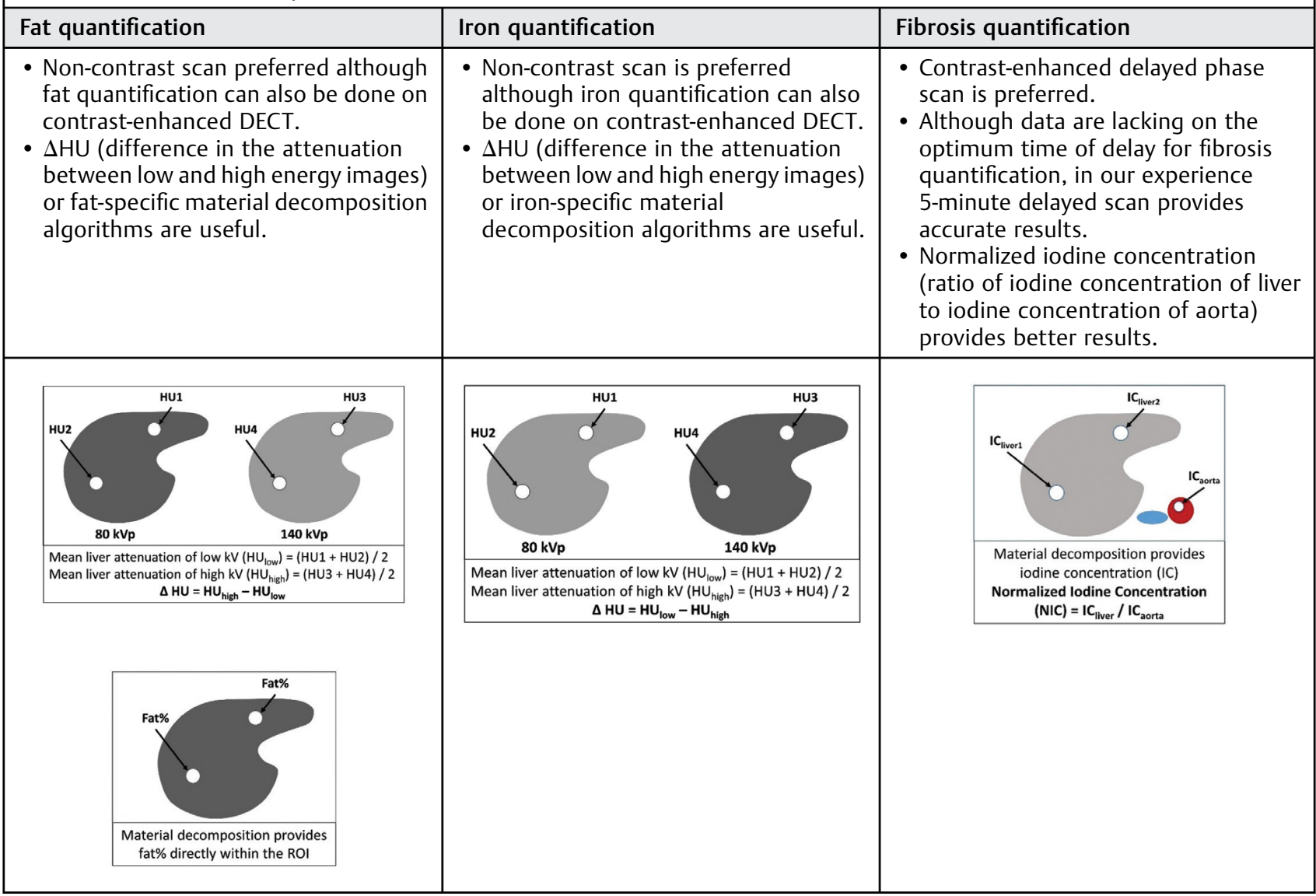

patients. The DECT- $\triangle$ HU showed similar excellent performance in diagnosing iron overload compared with MRI. The concurrent presence of liver fat did not affect the DECT performance in this study. Luo et al found that virtual iron concentration on DECT showed a significant correlation with $\mathrm{R}^{*}$ and MRI measured liver iron content $(r=0.89$ and 0.87 , respectively; $p<0.001){ }^{80}$ This study also suggested that DECT has similar diagnostic performance as MRI. A study by Werner et al showed a strong correlation between virtual iron content on DECT and serum ferritin in patients of transfusional hemosiderosis $(r=0.62, p<0.001) .{ }^{81}$ In a retrospective study by Ma et al, the authors showed a strong correlation between liver DECT- $\Delta \mathrm{HU}$ and $\mathrm{R} 2^{*}$ values in MRI $(r=0.83, p<0.001) .^{52}$

Unlike SECT, which underestimates fat in the presence of iron and vice versa, several phantom and animal studies have shown that DECT can accurately quantify iron, even in the presence of $\mathrm{fat}^{52,82,83}$ and vice versa. $^{52,83,84}$ In contrast, several other studies have suggested that iron and fat affect the measurement of each other on DECT. ${ }^{85-87}$ A recent study also suggested that the phase of contrast-enhanced scan (arterial, portal venous, and delayed) significantly affects the hepatic iron measurements on DECT. ${ }^{88}$ These confounding factors need to be studied further, and iron-specific algorithms, which are immune to these confounding effects, have to be developed before DECT can be recommended for routine use in this setting.

A summary of suggestions for practical applications of DECT in the quantification of hepatic fat, fibrosis, and iron content is given in - Table 4 .

\section{Limitations}

There are a few limitations to the routine use of DECT in diffuse liver diseases. The major limitation is the high cost of 
the scanners, additional software required for post-processing, and the need for larger data storage capacity. However, with the increasing number of installations, demands, and awareness of its considerable clinical utilities, the cost is expected to gradually reduce. Another limitation is the difference in the technique of DECT between different vendors. There are not enough studies comparing intervendor and interscanner variability with respect to the application of DECT in diffuse liver diseases. This may limit the uniformity of the study results. When DECT was first introduced, radiation dose was the main concern. However, later multiple studies have shown that DECT does not increase radiation dose compared with conventional CT and it is well within the ACR standard reference upper limit of $25 \mathrm{mGy}$ for abdominal $\mathrm{CT}{ }^{89-93}$ The presence of multiple material elements in the same area could affect the measurement of fat, iodine, or iron. It is still not clear whether the presence of fat and iron in the same voxel results in reduced performance of DECT. Active inflammation in the parenchyma, which is a key component of NASH and other chronic liver diseases, ${ }^{94-102}$ is difficult to evaluate with an imaging modality such as DECT. Hence, a complete assessment will have to involve imaging in conjunction with other tests for inflammation.

\section{Conclusion}

Dual-energy CT is still in its infancy and most of its applications are still in the research phase and not yet in wide clinical use. With exponential technological advances in scanner hardware, material decomposition algorithms, and image reconstruction software, the role of DECT will continue to grow in body imaging, and diffuse liver diseases is not an exception. However, MRI and its applications will remain the imaging gold standard for quantifying liver fat, iron, and fibrosis. The results from a majority of preliminary studies on the role of DECT in diffuse liver diseases are promising. However, larger cohort studies are needed to further validate these results before they come into routine clinical practice. Optimum application of DECT in routine abdominal CT protocols would not only give additional information for better patient management but could also potentially prevent unnecessary biopsies.

\section{Conflict of Interest}

None declared.

\section{References}

1 Hounsfield GN. Computerized transverse axial scanning (tomography). 1. Description of system. Br J Radiol 1973;46(552):1016-1022

2 Flohr TG, McCollough CH, Bruder H, et al. First performance evaluation of a dual-source CT (DSCT) system. Eur Radiol 2006; 16(02):256-268

3 Sebastiani G. Non-invasive assessment of liver fibrosis in chronic liver diseases: implementation in clinical practice and decisional algorithms. World J Gastroenterol 2009;15(18):2190-2203

4 Bravo AA, Sheth SG, Chopra S. Liver biopsy. N Engl J Med 2001; 344(07):495-500

5 Baranova A, Lal P, Birerdinc A, Younossi ZM. Non-invasive markers for hepatic fibrosis. BMC Gastroenterol 2011;11:91
6 Chin JL, Pavlides M, Moolla A, Ryan JD. Non-invasive markers of liver fibrosis: adjuncts or alternatives to liver biopsy? Front Pharmacol 2016;7:159https://www.frontiersin.org/articles/ 10.3389/fphar.2016.00159/full cited 2020May10 [Internet]

7 Olson MC, Reeder SB, Venkatesh SK. Quantitative MRI biomarkers of diffuse liver disease. Adv Clin Radiol. 2019;1:55-69

8 Curtis WA, Fraum TJ, An H, Chen Y, Shetty AS, Fowler KJ. Quantitative MRI of diffuse liver disease: current applications and future directions. Radiology 2019;290(01):23-30

9 Bannas P, Kramer H, Hernando D, et al. Quantitative magnetic resonance imaging of hepatic steatosis: validation in ex vivo human livers. Hepatology 2015;62(05):1444-1455

10 Rutherford RA, Pullan BR, Isherwood I. Measurement of effective atomic number and electron density using an EMI scanner. Neuroradiology 1976;11(01):15-21

11 Kruger RA, Riederer SJ, Mistretta CA. Relative properties of tomography, K-edge imaging, and K-edge tomography. Med Phys 1977;4(03):244-249

12 Lamb P, Sahani DV, Fuentes-Orrego JM, Patino M, Ghosh A, Mendonça PRS. Stratification of patients with liver fibrosis using dual-energy CT. IEEE Trans Med Imaging 2015;34(03):807-815

13 McCollough CH, Leng S, Yu L, Fletcher JG. Dual- and multi-energy CT: principles, technical approaches, and clinical applications. Radiology 2015;276(03):637-653

14 Patino M, Prochowski A, Agrawal MD, et al. Material separation using dual-energy CT: current and emerging applications. Radiographics 2016;36(04):1087-1105

15 Wilkins T, Tadkod A, Hepburn I, Schade RR. Nonalcoholic fatty liver disease: diagnosis and management. Am Fam Physician 2013;88(01):35-42

16 Fuster D, Samet JH. Alcohol use in patients with chronic liver disease. N Engl J Med 2018;379(13):1251-1261

17 Abenavoli L, Masarone M, Peta V, et al. Insulin resistance and liver steatosis in chronic hepatitis $\mathrm{C}$ infection genotype 3 . World J Gastroenterol 2014;20(41):15233-15240

18 Shigefuku R, Takahashi H, Nakano H, et al. Correlations of hepatic hemodynamics, liver function, and fibrosis markers in nonalcoholic fatty liver disease: comparison with chronic hepatitis related to hepatitis C virus. Int J Mol Sci 2016;17(09): E1545https://www.ncbi.nlm.nih.gov/pmc/articles/PMC5037819/ cited 2021Jun13 [Internet]

19 Satapathy SK, Kuwajima V, Nadelson J, Atiq O, Sanyal AJ. Druginduced fatty liver disease: an overview of pathogenesis and management. Ann Hepatol 2015;14(06):789-806

20 Ogawa Y, Murata Y, Nishioka A, Inomata T, Yoshida S. Tamoxifeninduced fatty liver in patients with breast cancer. Lancet 1998; 351(9104):725

21 Wakatsuki A, Ogawa Y, Saibara T, Okatani Y, Fukaya T. Size and oxidative susceptibility of low-density lipoprotein particles in breast cancer patients with tamoxifen-induced fatty liver. 6

22 Woods CP, Hazlehurst JM, Tomlinson JW. Glucocorticoids and non-alcoholic fatty liver disease. J Steroid Biochem Mol Biol 2015;154:94-103

23 Younossi ZM, Koenig AB, Abdelatif D, Fazel Y, Henry L, Wymer M. Global epidemiology of nonalcoholic fatty liver disease-Metaanalytic assessment of prevalence, incidence, and outcomes. Hepatology 2016;64(01):73-84

24 Marchesini G, Bugianesi E, Forlani G, et al. Nonalcoholic fatty liver, steatohepatitis, and the metabolic syndrome. Hepatology 2003;37(04):917-923

25 Alberti KGMM, Eckel RH, Grundy SM, et al; International Diabetes Federation Task Force on Epidemiology and Prevention Hational Heart, Lung, and Blood Institute American Heart Association World Heart Federation International Atherosclerosis Society International Association for the Study of Obesity. Harmonizing the metabolic syndrome: a joint interim statement of the International Diabetes Federation Task Force on Epidemiology and Prevention; National Heart, Lung, and Blood Institute; 
American Heart Association; World Heart Federation; International Atherosclerosis Society; and International Association for the Study of Obesity. Circulation 2009;120(16):1640-1645

26 Caldwell SH, Crespo DM. The spectrum expanded: cryptogenic cirrhosis and the natural history of non-alcoholic fatty liver disease. J Hepatol 2004;40(04):578-584

27 d'Assignies G, Fayard C, Leitao H, et al. Liver steatosis assessed by preoperative MRI: an independent risk factor for severe complications after major hepatic resection. Surgery 2016;159(04): 1050-1057

28 Degasperi E, Colombo M. Distinctive features of hepatocellular carcinoma in non-alcoholic fatty liver disease. Lancet Gastroenterol Hepatol 2016;1(02):156-164

29 Majumdar A, Verbeek J, Tsochatzis EA. Non-alcoholic fatty liver disease: Current therapeutic options. Curr Opin Pharmacol 2021;61:98-105

30 Ferraioli G, Soares Monteiro LB. Ultrasound-based techniques for the diagnosis of liver steatosis. World J Gastroenterol 2019;25 (40):6053-6062

31 Kramer H, Pickhardt PJ, Kliewer MA, et al. Accuracy of liver fat quantification with advanced CT, MRI, and ultrasound techniques: prospective comparison with MR spectroscopy. Am J Roentgenol 2017;208(01):92-100

32 Reeder SB, Hu HH, Sirlin CB. Proton density fat-fraction: a standardized MR-based biomarker of tissue fat concentration. J Magn Reson Imaging 2012;36(05):1011-1014

33 Petta S, Maida M, Macaluso FS, et al. The severity of steatosis influences liver stiffness measurement in patients with nonalcoholic fatty liver disease. Hepatology 2015;62(04):1101-1110

34 Sasso M, Miette V, Sandrin L, Beaugrand M. The controlled attenuation parameter (CAP): a novel tool for the non-invasive evaluation of steatosis using Fibroscan. Clin Res Hepatol Gastroenterol 2012;36(01):13-20

35 Kumar M, Rastogi A, Singh T, et al. Controlled attenuation parameter for non-invasive assessment of hepatic steatosis: does etiology affect performance? J Gastroenterol Hepatol 2013;28(07):1194-1201

36 Zhang YN, Fowler KJ, Hamilton G, et al. Liver fat imaging-a clinical overview of ultrasound, CT, and MR imaging. Br J Radiol 2018;91(1089):20170959

37 Li Q, Dhyani M, Grajo JR, Sirlin C, Samir AE. Current status of imaging in nonalcoholic fatty liver disease. World J Hepatol 2018;10(08):530-542

38 Sagir Kahraman A, Karakas HM, Kirimlioglu H, Kahraman B, Yilmaz S, Kirimlioglu V. The assessment of hepatosteatosis in living-donor liver transplant: comparison of liver attenuation index and histopathologic results. Exp Clin Transplant 2017;15 (01):69-77

39 Park SH, Kim PN, Kim KW, et al. Macrovesicular hepatic steatosis in living liver donors: use of CT for quantitative and qualitative assessment. Radiology 2006;239(01):105-112

40 Lee SW, Park SH, Kim KW, et al. Unenhanced CT for assessment of macrovesicular hepatic steatosis in living liver donors: comparison of visual grading with liver attenuation index. Radiology 2007;244(02):479-485

41 Iwasaki M, Takada Y, Hayashi M, et al. Noninvasive evaluation of graft steatosis in living donor liver transplantation. Transplantation 2004;78(10):1501-1505

42 Bohte AE, van Werven JR, Bipat S, Stoker J. The diagnostic accuracy of US, CT, MRI and 1H-MRS for the evaluation of hepatic steatosis compared with liver biopsy: a meta-analysis. Eur Radiol 2011;21(01):87-97

43 Mendler MH, Bouillet P, Le Sidaner A, et al. Dual-energy CT in the diagnosis and quantification of fatty liver: limited clinical value in comparison to ultrasound scan and single-energy CT, with special reference to iron overload. J Hepatol 1998;28(05):785-794

44 Hyodo T, Yada N, Hori M, et al. Multimaterial decomposition algorithm for the quantification of liver fat content by using fast- kilovolt-peak switching dual-energy CT: clinical evaluation. Radiology 2017;283(01):108-118

45 Corrias G, Erta M, Sini M, et al. Comparison of multimaterial decomposition fat fraction with DECT and proton density fat fraction with IDEAL IQ MRI for quantification of liver steatosis in a population exposed to chemotherapy. Dose Response 2021;19 (02):1559325820984938

46 Patel BN, Kumbla RA, Berland LL, Fineberg NS, Morgan DE. Material density hepatic steatosis quantification on intravenous contrast-enhanced rapid kilovolt (peak)-switching single-source dual-energy computed tomography. J Comput Assist Tomogr 2013;37(06):904-910

47 Artz NS, Hines CDG, Brunner ST, et al. Quantification of hepatic steatosis with dual-energy computed tomography: comparison with tissue reference standards and quantitative magnetic resonance imaging in the ob/ob mouse. Invest Radiol 2012;47(10): 603-610

48 Sun T, Lin X, Chen K. Evaluation of hepatic steatosis using dualenergy CT with MR comparison. Front Biosci 2014;19:1377-1385

49 Hur BY, Lee JM, Hyunsik W, et al. Quantification of the fat fraction in the liver using dual-energy computed tomography and multimaterial decomposition. J Comput Assist Tomogr 2014;38(06): 845-852

50 Noh H, Song X, Heo S, et al. Comparative study of ultrasonography, computed tomography, magnetic resonance imaging, and magnetic resonance spectroscopy for the diagnosis of fatty liver in a rat model. J Korean Soc Radiol 2017;76:14

51 Wang Q, Shi G, Qi X, Fan X, Wang L. Quantitative analysis of the dual-energy CT virtual spectral curve for focal liver lesions characterization. Eur J Radiol 2014;83(10):1759-1764

52 Ma J, Song Z-Q Yan F-H. Separation of hepatic iron and fat by dual-source dual-energy computed tomography based on material decomposition: an animal study. PLoS One 2014;9(10): e110964

53 Cao Q Shang S, Han X, Cao D, Zhao L. Evaluation on heterogeneity of fatty liver in rats: a multiparameter quantitative analysis by dual energy CT. Acad Radiol 2019;26(05):e47-e55

54 Toepker M, Moritz T, Krauss B, et al. Virtual non-contrast in second-generation, dual-energy computed tomography: reliability of attenuation values. Eur J Radiol 2012;81(03):e398-e405

55 De Cecco CN, Darnell A, Macías N, et al. Virtual unenhanced images of the abdomen with second-generation dual-source dual-energy computed tomography: image quality and liver lesion detection. Invest Radiol 2013;48(01):1-9

56 De Cecco CN, Buffa V, Fedeli S, et al. Dual energy CT (DECT) of the liver: conventional versus virtual unenhanced images. Eur Radiol 2010;20(12):2870-2875

57 Sahni VA, Shinagare AB, Silverman SG. Virtual unenhanced CT images acquired from dual-energy $C T$ urography: accuracy of attenuation values and variation with contrast material phase. Clin Radiol 2013;68(03):264-271

58 Schuppan D, Afdhal NH. Liver cirrhosis. Lancet 2008;371 (9615):838-851

59 Friedman SL. Liver fibrosis - from bench to bedside. J Hepatol 2003;38(Suppl 1):S38-S53

60 Barr RG, Ferraioli G, Palmeri ML, et al. Elastography assessment of liver fibrosis: Society of Radiologists in Ultrasound Consensus Conference Statement. Radiology 2015;276(03):845-861

61 Ferraioli G, Tinelli C, Dal Bello B, Zicchetti M, Filice G, Filice CLiver Fibrosis Study Group. Accuracy of real-time shear wave elastography for assessing liver fibrosis in chronic hepatitis C: a pilot study. Hepatology 2012;56(06):2125-2133

62 Sandrin L, Fourquet B, Hasquenoph JM, et al. Transient elastography: a new noninvasive method for assessment of hepatic fibrosis. Ultrasound Med Biol 2003;29(12):1705-1713

63 Huwart L, Sempoux C, Vicaut E, et al. Magnetic resonance elastography for the noninvasive staging of liver fibrosis. Gastroenterology 2008;135(01):32-40 
64 Guo SL, Su LN, Zhai YN, et al. The clinical value of hepatic extracellular volume fraction using routine multiphasic contrast-enhanced liver CT for staging liver fibrosis. Clin Radiol 2017;72(03):242-246

65 Yoon JH, Lee LM, Klotz E, Jeon JH, Lee KB, Han JK, et al. Estimation of hepatic extracellular volume fraction using multiphasic liver computed tomography for hepatic fibrosis grading. Invest Radiol 2015;50(04):290-296

66 Bandula S, Punwani S, Rosenberg WM, et al. Equilibrium contrast-enhanced CT imaging to evaluate hepatic fibrosis: initial validation by comparison with histopathologic sampling. Radiology 2015;275(01):136-143

67 Zissen MH, Wang ZJ, Yee J, Aslam R, Monto A, Yeh BM. Contrastenhanced CT quantification of the hepatic fractional extracellular space: correlation with diffuse liver disease severity. Am J Roentgenol 2013;201(06):1204-1210

68 Marri UK, Das PShalimar Kalaivani M, Srivastava DN, Madhusudhan KS. Noninvasive staging of liver fibrosis using 5-minute delayed dual-energy CT: comparison with US elastography and correlation with histologic findings. Radiology 2021;298(03):600-608

69 Lv P, Lin X, Gao J, Chen K. Spectral CT: preliminary studies in the liver cirrhosis. Korean J Radiol 2012;13(04):434-442

70 Fuentes J, Patino M, Hayano K, Andrabi Y, Agrawal M, Sahani D. Detection and stratification of liver fibrosis using dual energy CT (DECT) [Internet]. Scientific papers, Radiological Society of North America 2014 Scientific Assembly and Annual Meeting 2014 [cited 2018 Dec 2]. Available at: http://archive.rsna.org/ 2014/14015323.html

71 Sofue K, Tsurusaki M, Mileto A, et al. Dual-energy computed tomography for non-invasive staging of liver fibrosis: Accuracy of iodine density measurements from contrast-enhanced data. Hepatol Res 2018;48(12):1008-1019

72 Hilgard P, Gerken G. Liver cirrhosis as a consequence of iron overload caused by hereditary nonspherocytic hemolytic anemia. World J Gastroenterol 2005;11(08):1241-1244

73 Batts KP. Iron overload syndromes and the liver. Mod Pathol 2007;20(01, Suppl 1):S31-S39

74 Abergel A, Ruivard M, Bonny C. [Iron overload and chronic liver diseases]. Rev Prat 2006;56(19):2130-2134

75 Milic S, Mikolasevic I, Orlic L, et al. The Role of Iron and Iron Overload in Chronic Liver Disease. Med Sci Monit 2016; 22:2144-2151

76 Ganne-Carrié N, Christidis C, Chastang C, et al. Liver iron is predictive of death in alcoholic cirrhosis: a multivariate study of 229 consecutive patients with alcoholic and/or hepatitis $C$ virus cirrhosis: a prospective follow up study. Gut 2000;46(02):277-282

77 Henninger B, Alustiza J, Garbowski M, Gandon Y. Practical guide to quantification of hepatic iron with MRI. Eur Radiol 2020;30 (01):383-393

78 Labranche R, Gilbert G, Cerny M, et al. Liver iron quantification with MR imaging: a primer for radiologists. Radiographics 2018; 38(02):392-412

79 Joe E, Kim SH, Lee KB, et al. Feasibility and accuracy of dualsource dual-energy CT for noninvasive determination of hepatic iron accumulation. Radiology 2012;262(01):126-135

80 Luo XF, Xie XQ Cheng S, et al. Dual-energy CT for patients suspected of having liver iron overload: can virtual iron content imaging accurately quantify liver iron content? Radiology 2015; 277(01):95-103

81 Werner S, Krauss B, Haberland U, et al. Dual-energy CT for liver iron quantification in patients with haematological disorders. Eur Radiol 2019;29(06):2868-2877

82 Fischer MA, Reiner CS, Raptis D, et al. Quantification of liver iron content with CT-added value of dual-energy. Eur Radiol 2011;21 (08):1727-1732
83 Peng Y, Ye J, Liu C, et al. Simultaneous hepatic iron and fat quantification with dual-energy CT in a rabbit model of coexisting iron and fat. Quant Imaging Med Surg 2021;11(05): 2001-2012

84 Fischer MA, Gnannt R, Raptis D, et al. Quantification of liver fat in the presence of iron and iodine: an ex-vivo dual-energy CT study. Invest Radiol 2011;46(06):351-358

85 Hyodo T, Hori M, Lamb P, et al. Multimaterial decomposition algorithm for the quantification of liver fat content by using fastkilovolt-peak switching dual-energy CT: experimental validation. Radiology 2017;282(02):381-389

86 Xie T, Li Y, He G, Zhang Z, Shi Q Cheng G. The influence of liver fat deposition on the quantification of the liver-iron fraction using fast-kilovolt-peak switching dual-energy $\mathrm{CT}$ imaging and material decomposition technique: an in vitro experimental study. Quant Imaging Med Surg 2019;9(04):654-661

87 Zheng X, Ren Y, Phillips WT, et al. Assessment of hepatic fatty infiltration using spectral computed tomography imaging: a pilot study. J Comput Assist Tomogr 2013;37(02):134-141

88 Basso L, Baldi D, Mannelli L, Cavaliere C, Salvatore M, Brancato V. Investigating dual-energy CT post-contrast phases for liver iron quantification: a preliminary study. Dose Response 2021;19 (02):15593258211011359

89 Foley WD, Shuman WP, Siegel MJ, et al. White Paper of the Society of Computed Body Tomography and Magnetic Resonance on Dual-Energy CT, Part 2: radiation dose and iodine sensitivity. J Comput Assist Tomogr 2016;40(06):846-850

90 Purysko AS, Primak AN, Baker ME, et al. Comparison of radiation dose and image quality from single-energy and dual-energy CT examinations in the same patients screened for hepatocellular carcinoma. Clin Radiol 2014;69(12):e538-e544

91 Kulkarni NM, Pinho DF, Kambadakone AR, Sahani DV. Emerging technologies in CT- radiation dose reduction and dual-energy CT. Semin Roentgenol 2013;48(03):192-202

92 Jepperson MA, Cernigliaro JG, Ibrahim SH, Morin RL, Haley WE, Thiel DD. In vivo comparison of radiation exposure of dualenergy CT versus low-dose CT versus standard CT for imaging urinary calculi. J Endourol 2015;29(02):141-146

93 Henzler T, Fink C, Schoenberg SO, Schoepf UJ. Dual-energy CT: radiation dose aspects. AJR Am J Roentgenol 2012;199(5, Suppl) S16-S25

94 Martínez-Esparza M, Tristán-Manzano M, Ruiz-Alcaraz AJ, García-Peñarrubia P. Inflammatory status in human hepatic cirrhosis. World J Gastroenterol 2015;21(41):11522-11541

95 Marra F. Chemokines in liver inflammation and fibrosis. Front Biosci 2002;7:d1899-d1914

96 Wang HJ, Gao B, Zakhari S, Nagy LE. Inflammation in alcoholic liver disease. Annu Rev Nutr 2012;32:343-368

97 Gao B, Tsukamoto H. Inflammation in alcoholic and nonalcoholic fatty liver disease: friend or foe? Gastroenterology 2016;150 (08):1704-1709

98 Yeh MM, Brunt EM. Pathology of nonalcoholic fatty liver disease. Am J Clin Pathol 2007;128(05):837-847

99 Takahashi Y, Fukusato T. Histopathology of nonalcoholic fatty liver disease/nonalcoholic steatohepatitis. World J Gastroenterol 2014;20(42):15539-15548

100 Parthasarathy G, Revelo X, Malhi H. Pathogenesis of nonalcoholic steatohepatitis: an overview. Hepatol Commun 2020;4(04): 478-492

101 Schuster S, Cabrera D, Arrese M, Feldstein AE. Triggering and resolution of inflammation in NASH. Nat Rev Gastroenterol Hepatol 2018;15(06):349-364

102 Farrell GC, van Rooyen D, Gan L, Chitturi S. NASH is an inflammatory disorder: pathogenic, prognostic and therapeutic Implications. Gut Liver 2012;6(02):149-171 